\title{
New water strider species of Eurymetra from Madagascar (Hemiptera: Heteroptera: Gerridae)
}

\author{
Herbert ZETTEL \\ $2^{\text {nd }}$ Zoological Department, Natural History Museum, Burgring 7, 1010 Vienna, Austria; e-mail: herbert.zettel@nhm-wien.ac.at
}

$$
\begin{aligned}
& \text { Accepted: } \\
& 7^{\text {th }} \text { January } 2020 \\
& \text { Published online: } \\
& 29^{\text {th }} \text { February } 2020
\end{aligned}
$$

\begin{abstract}
The Madagascan material of the halobatine genus Eurymetra Esaki, 1926 (Hemiptera: Heteroptera: Gerridae: Halobatinae), which is deposited at the Natural History Museum Vienna, is revised. A close examination of "Eurymetra madagascariensis Poisson, 1945" revealed two new species, Eurymetra santamariae sp. nov. and Eurymetra papaceki sp. nov. A definition of the newly established Eurymetra madagascariensis species group is provided as well as keys to the freshwater halobatine genera and to Eurymetra species known from Madagascar.
\end{abstract}

Key words. Hemiptera, Heteroptera, Gerridae, Halobatinae, Eurymetra, Eurymetropsielloides, freshwater, taxonomy, new species, key, Madagascar, Afrotropical Region

Zoobank: http://zoobank.org/ urn:1sid:zoobank.org:pub:A92539F8-4273-415B-A985-E0A0F03CE6A6

(C) 2020 The Authors. This work is licensed under the Creative Commons Attribution-NonCommercial-NoDerivs 3.0 Licence.

\section{Introduction}

Madagascar is home to an interesting and rich, but still inadequately studied diversity of semiaquatic bugs (Gerromorpha) (e.g., Poisson 1945, 1952, 1956, PolHemus \& Andersen 2015). Most of the freshwater species are endemic. Only fifteen species of true water striders (Gerridae) were reported from Madagascar in the past, four of which inhabit the sea (Halobates spp.; RoMÁn-PALACIOS et al. 2018) and eleven the freshwater. Of these eleven species, seven are endemic to the region (Madagascar and Reunion), one has an endemic subspecies, and three are non-endemic (Andersen 1982, Polhemus \& Polhemus 2002, Damgand et al. 2014, Román-Palacios et al. 2018). Of the subfamily Halobatinae - which is speciose in Asia (e.g., Chen \& Nieser 1993a, b; Chen \& Zettel 1999; TRAN \& ZETTEL 2019) - only two freshwater species were reported from Madagascar: Eurymetra madagascariensis Poisson, 1945 and Eurymetropsielloides milloti Poisson, 1956 (Poisson 1945, 1956).

Eurymetra Esaki, 1926 presently contains seven species, six inhabiting the African continent and one Madagascar (Román-PAlacios et al. 2018). No taxonomic study has been carried out on Eurymetra madagasca- riensis since its original description. PoIsson (1945) described only the apterous female, the male has remained undescribed.

The Natural History Museum in Vienna keeps 26 specimens of Eurymetra from Madagascar that were formerly identified as Eurymetra madagascariensis. However, a closer examination of the specimens revealed an unexpected diversity. In this study, I describe two new species.

Because Eurymetra is rather heterogeneous in its morphological characters, it seems possible that it is not monophyletic. In their molecular analysis, Román-PALACIOS et al. (2018) included two species of Eurymetra: E. natalensis Distant, 1903 (the type species) and E. madagascariensis. However, as the other African genera (Eurymetropsis Poisson, 1948, Eurymetropsiella Poisson, 1950, and Eurymetropsielloides Poisson, 1956) could not be included, the monophyly of Eurymetra remains questionable.

The species from Madagascar form a morphologically distinct species group that is defined below. In their colour pattern, they resemble Eurymetropsielloides Poisson, 1956, the only other freshwater genus known from Madagascar. However, there are strong differences in the males' antennae and in the females' tergal structures. 


\section{Material and methods}

I studied 26 specimens of Eurymetra from the Natural History Museum in Vienna (NHMW).

Insects were examined with a Leica Wild M10 binocular microscope (max. 128× magnification); studies on parameres were made with an OLYMPUS BX40 compound microscope (max. 400× magnification). Drawings were made with the help of a camera lucida fixed to these microscopes.

Stacked digital images were taken with a Leica DFC490 camera attached to either a Leica MZ16 binocular microscope or a Leica Z16 APO zoom macroscope, using Leica Application Suite V3. Images were stacked with ZereneStacker 64-bit, and processed with Adobe Photoshop 7.0 (including addition of some broken antennal and leg segments by copying from one side to the other for aesthetic reasons).

Measurements and indices: All measurements are given in millimetres. Lengths of antennomeres (A1-A4) and leg parts $(\mathrm{Fe}=$ femur, $\mathrm{Ti}=$ tibia, $\mathrm{Ta}=$ tarsus $)$ were measured (only in holotypes, except protarsus and protibia in all specimens) in a straight position from their apex to the apex of the preceding antennomere or leg part. Length of A1 does not include the condylus.

BL body length: measured in dorsal view, from the apex of head to apex of proctiger;

BW body width: maximum width (at mesoacetabula), measured in dorsal view;

HW maximum head width: measured in dorsal view including compound eyes;
IO interocular width: minimum distance between compound eyes, measured in dorsal view;

PW pronotum width: maximum width of pronotum, measured in dorsal view;

$\mathrm{TaL}$ length of protarsus: measured from insertion point on protibia to apex;

TiL length of protibia: measured from base to apical protrusion;

$\mathrm{PHI}$ pronotal index: $\mathrm{PW} / \mathrm{HW} \times 100$;

TTI tibia-tarsal index: TaL $/ \mathrm{TiL} \times 100$.

\section{Taxonomy}

\section{Key to the freshwater halobatine genera of Madagascar}

1 Body moderately stout, BW / HW < 1.9; apterous morph without shiny areas on thoracic nota and tergites; metasternal scent gland structure conical. Male: antenna modified, stouter than in female; antennomeres $1-3$ ventrally bearing fine silvery pubescence; meso-metanotal suture of apterous male medially incomplete. - Female: tergites 1-2 without velvety patch.

Eurymetropsielloides Poisson, 1956

- Body very stout, BW / HW > 1.9; apterous morph with shiny areas on thoracic nota and tergites (in males sometimes indistinct); metasternal scent gland structure circular (Fig. 3). - Male: antenna as slender as in female, antennomere 1 without silvery pubescence (Fig. 1), antennomeres 2-3 with inconspicuous dark pubescence; meso-metanotal suture of apterous male medially complete. - Female: tergites 1-2 with large velvety patch (Fig. 2).

Eurymetra Esaki, 1926

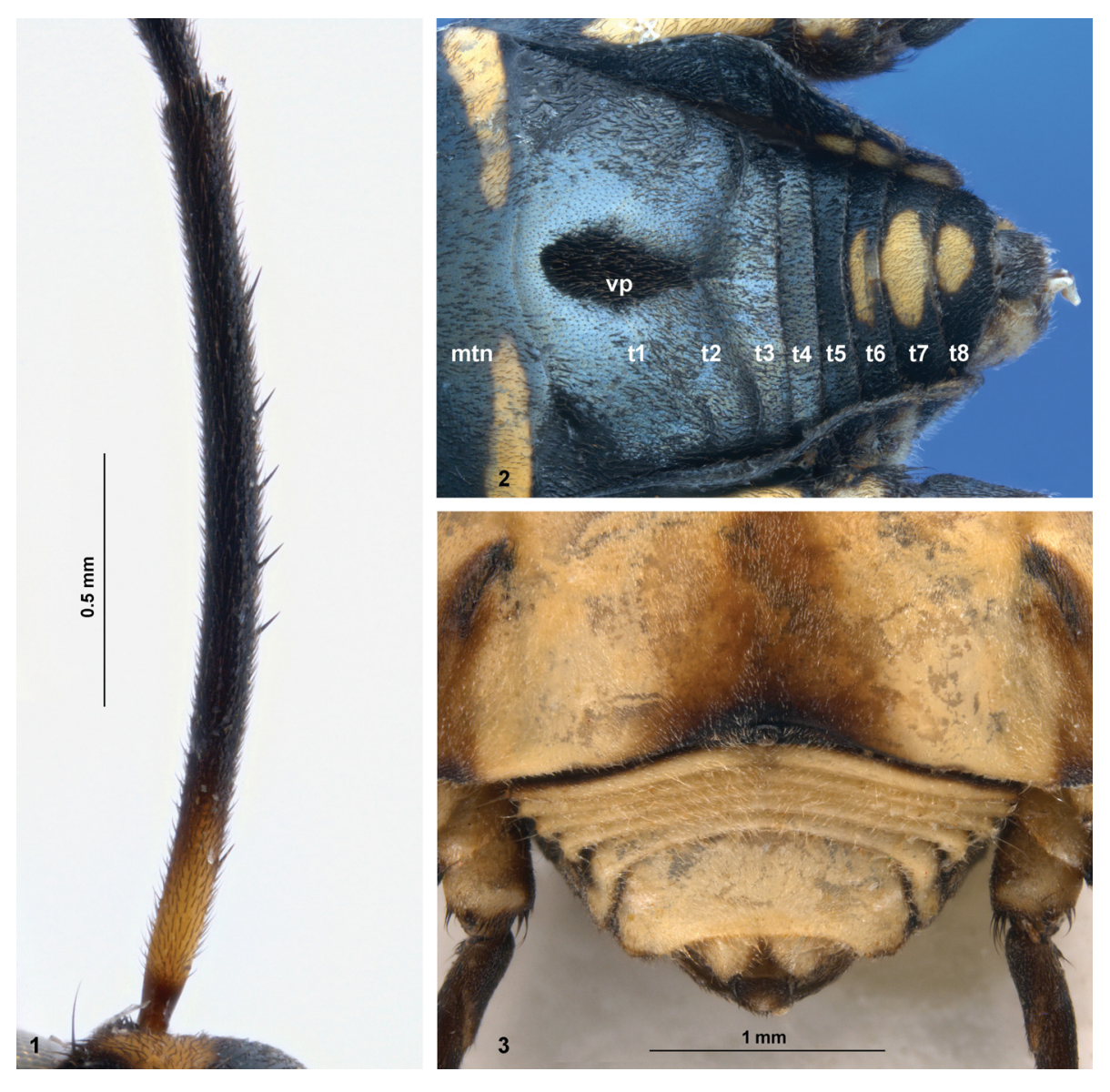

Figs 1-3. Diagnostic characters of the Eurymetra madagascariensis species group (images of E. papaceki sp. nov.): 1 - first antennomere of left antenna of a male, illustrating the sparsely distributed setae; 2 -abdomen of a female in slightly oblique dorsal view, illustrating the velvety patch; 3 -thorax (in part) and abdomen of a female in ventral view, illustrating the roundish elevation of metasternal scent gland opening and exposed gonocoxae 1. Abbreviations: $\mathrm{mtn}$ - metanotum; $\mathrm{t} 1-\mathrm{t} 8$ tergites $1-8 ; \mathrm{vp}-$ velvety patch. 


\section{The Eurymetra madagascariensis species group}

Diagnosis. Body stout, size small to moderate, BL 3.7-4.8, BW 2.62-3.40. Dorsum relatively dark coloured, pattern as in Figures 4-9; head with large black patch between eyes; on antenna, only base of antennomere 1 yellow; mesopleura with wide, completely isolated, black stripe; tergites 1-4 (often also 5) black, without yellow marks. Eye very large, posteriorly reaching or surpassing anterior margin of mesopleuron. Antenna long, very slender and unmodified in both sexes; antennomere 1 with a row of short setae (Fig. 1). Pronotum small, lateral margins embraced by eyes. Metasternal scent gland opening situated on a low round tubercle (Fig. 3). Fore leg of male hardly modified, but longer than in female; erect pilosity on flexor side of femur slightly denser; apical process on tibia slightly more curved. Genitalia of male very small, simple and uniform: Pygophore squared, apically truncated, ca. 1.2 times as long as wide; proctiger elongated, slightly surpassing pygophore, including basal processes ca. 1.6 times as long as wide, with evenly rounded apex; paramere small, more or less upcurved, without setae, with narrowly rounded apex (Figs 10-12). Tergite 1 of female with large patch of velvety dark pilosity (Fig. 2). Sternite 7 of female short and truncated; gonocoxa 1 exposed.

Comparative notes. The distinct patch of velvety pilosity on tergites 1-2 of females, first described by PoIsson (1945, as "tache «scutellaire» noir mat"), is unknown from other halobatine water striders. The type species of Eurymetra, E. natalensis (Distant, 1903), and three obviously closely related forms, E. angolensis Hoberlandt, 1951, E. nitidula (Esaki, 1926), and E. pauliani Poisson, 1941 clearly differ by their rich yellow colouration, large size $(\mathrm{BL}>5 \mathrm{~mm}$, except for E. nitidula), and comparatively small eyes; their metasternal scent gland opening is not distinctly elevated (this character remains undescribed for E. pauliani and $E$. nitidula). Two smaller, poorly known species from Africa, E. aethiops (Distant, 1903) and E. africana Poisson, 1947 are more similar in colour pattern to the E. madagascariensis group, but they do not possess a velvety patch in females, either.

Diversity and distribution. At present three species endemic to Madagascar are known. It is expected that more species will be discovered when material from other parts of the island becomes available.

\section{Key to the Eurymetra species from Madagascar}

1 In lateral view, eye just reaching base of mesopleuron. Large species, body length $4.6-4.8 \mathrm{~mm}$, head width 1.60-1.67 mm. Dorsal surface of body predominately shiny in both sexes. Protarsi comparatively long, TTI = 36-43. Paramere near to base wide (Fig. 12).

\section{E. papaceki sp. nov.}

- In lateral view, eye surpassing base of mesopleuron. Smaller species, body length $<3.9 \mathrm{~mm}$, head width $<$ $1.5 \mathrm{~mm}$; if larger (body length up to $4.5 \mathrm{~mm}$ ), then TTI $<34$. Dorsal surface with smaller shiny areas. Paramere near to base slender (Figs 10, 11).....
2 Pronotum very small, PHI $=75-80$. Metapleuron without yellow spot above spiracle. Protarsus of moderate length, TTI = 34-38. ....... E. santamariae sp. nov.

- Pronotum moderately small, PHI $=85-90$. Metapleuron above spiracle with yellow spot. Protarsus very short, TTI $=27-33$.

E. madagascariensis Poisson, 1945

\section{Eurymetra madagascariensis Poisson, 1945}

(Figs 4, 5, 10)

Eurymetra madagascariensis Poisson, 1945: 89. SYNTYPES: apterous females, coll. Muséum national d'Histoire naturelle, Paris (not examined): "Madagascar (Sicard 1930)" [no exact locality given].

Material examined (all in NHMW): $2 \hat{\partial}$ (apterous), Madagascar, Antsiranana Province, Nosy Be (Nossi-Bé) Island, Djabalahely, Ruisseau de Djabala, 22.viii.1958, leg. E. Pomeisl (191); 1 of (apterous), Madagascar, Antsiranana Province, Nosy Be (Nossi-Bé) Island, Androadroatra, Ruisseau d'Androadroatro, 23.viii.1958, leg. F. Starmühlner (FM175).

Redescription. Male. Measurements of non-type specimens $(\mathrm{n}=3)$ : BL 3.70-3.90; BW 2.62-2.81; HW 1.42-1.49; IO 0.48-0.51; PW 1.22-1.27; PHI 85-87; TiL 1.68-1.90; TaL 0.50-0.52; TTI 27-30.

Structural characteristics. Eyes large, posteriorly surpassing sides of pronotum; their minimum distance on average intermediate compared to other species. Antennomere 1 with row of ca. $2-5$ short oblique setae. Pronotum small, in dorsal view of specimen, as long as half of head length along midline. Apical process of protibia short, slender and weakly curved. Shiny areas of dorsum expanded: middle of pronotum and indistinct paired patches on mesonotum weakly shiny; metacetabulum with shiny area on medial half (indistinct in one specimen); metanotum and tergites 1-4 strongly shiny, almost reaching sides of most plates. Sutures between metanotum and tergites 1-3 visible, accentuated by narrow matt stripes. Paramere very narrow all over its length, weakly bent at midlength, distal part moderately narrowed (Fig. 10).

Colour. Yellow marks comparatively small (Figs 4). On head, anterior mark between antennal tubercles orange and more or less interrupted in middle. Paired marks on pronotum narrow, medially only slightly widened anteriorly, narrower than half-length of pronotum. Paired marks on mesonotum subtriangular, large, medially with straight parallel-sided margins. Paired marks on metanotum widely distant from each other. Metapleuron above spiracle with distinct yellow spot. Mark on metacetabulum either small, or larger and medioposteriorly extended. On abdomen, small yellow marks on tergites 6-7, and on laterotergites 6-7 (in one male 4-7). Body ventrally entirely yellow (except metasternum more or less infuscate).

Female (see also "Comparative notes" for syntypes): Measurements of non-type specimen: BL 3.70; BW 2.70; HW 1.42; IO 0.48; PW 1.25; PHI 88; TiL 1.57; TaL 0.49; TTI 31.

Structural characteristics. Similar to male. Apical process of protibia slender and straight. Shiny areas even more developed than in male: in addition, a large medial portion of pronotum and almost the entire mesonotum (except sides) shiny; metanotum and tergites 1-3 fused, 


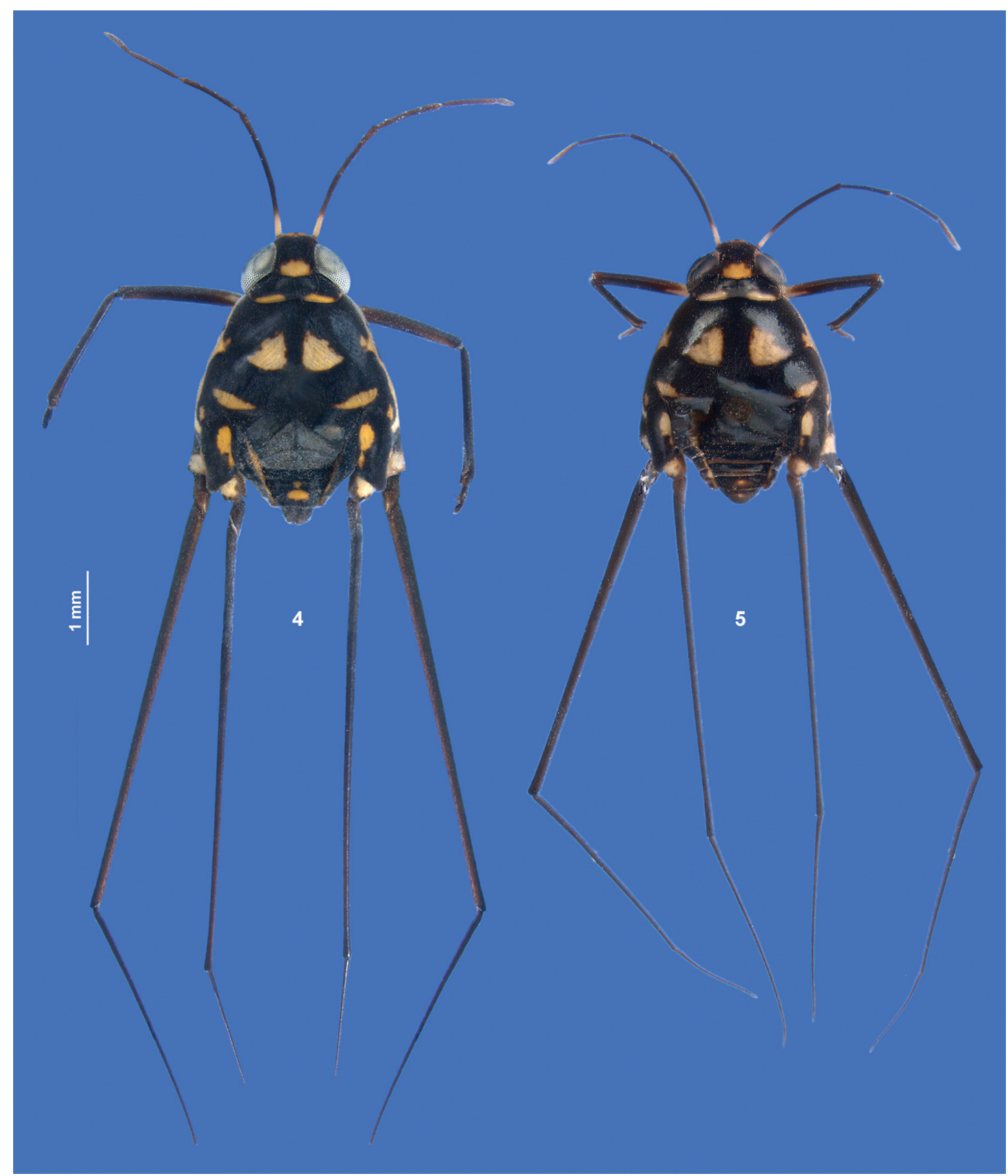

Figs 4-5. Eurymetra madagascariensis Poisson, 1945, habitus in dorsal aspect: 4 - male, 5 - female.

without matt stripes indicating sutures, shiny area only interrupted by velvety patch.

Colour. Similar to male (Fig. 5). On head, anterior mark between antennal tubercles interrupted in middle. Metapleuron above spiracle with yellow spot. Mark on metacetabulum moderate in size and medioposteriorly extended (in syntype large, fide Poisson 1945: fig. 3a). On abdomen, very small yellow marks on tergites 7-8 (in syntype 6-8, fide Poisson 1945: fig. 3a), and (slightly larger) on laterotergites $6-7$. Body ventrally entirely yellow, except metanotum strongly infuscated in middle.

Comparative notes. See key and comparative notes for other species. The conspecificity of the studied material with the syntypes, two females only, remains uncertain, although Raymond Poisson himself identified the four specimens as E. madagascariensis. The species identity is preliminarily fixed on three characters: i) the distinct lateral spot on the metapleuron, ii) the short protarsi, and iii) the normal-sized pronotum (in comparison to the small pronotum of $E$. santamariae sp. nov.). On the other hand, the syntypes are reportedly larger than the specimens in the Natural History Museum Vienna (BL 4.25-4.5 mm, according to PoIssON 1945) and there are also some differences in colour pattern. For example, according to PoIsson (1945: fig. 3a) the mark on the metacetabulum is distinctly larger, and tergite 6 possesses a small yellow mark in the middle. Although the variation of colouration cannot be properly evaluated based on only two females, it cannot be excluded that the studied specimens do not represent E. madagascariensis, but a further undescribed species. Geographic conclusions cannot be properly drawn, since the type locality of E. madagascariensis is not specific. 


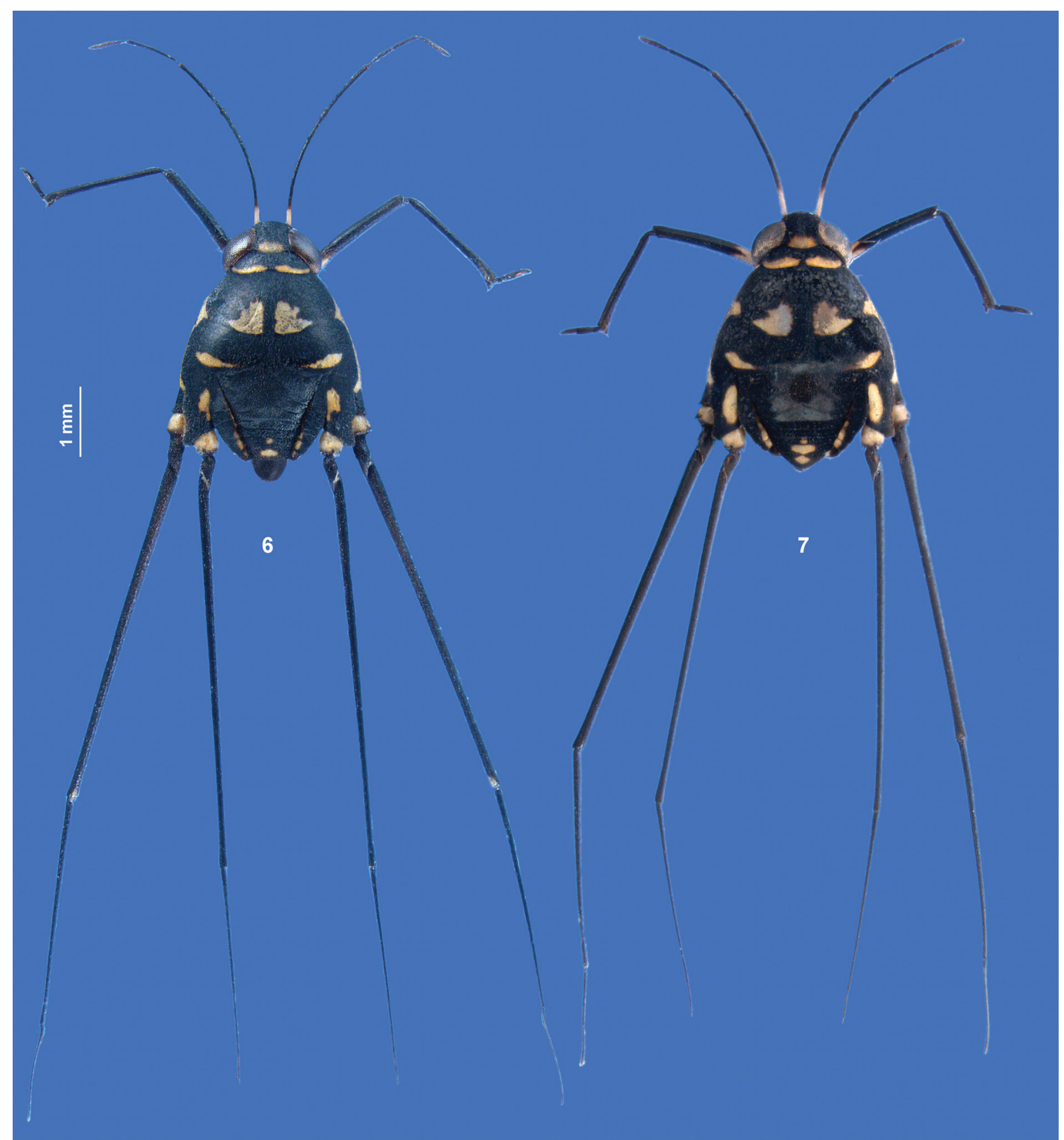

Figs 6-7. Eurymetra santamariae sp. nov., habitus in dorsal aspect: 6 - holotype, male; 7 - allotype, female.

However, it is known that in 1930 A. Sicard (year of collecting and collector of the types; see Poisson 1945) visited the northern mainland of Madagascar, not very distant from Nosy Be Island; see, e.g., Constant 2014).

\section{Eurymetra santamariae sp. nov.}

(Figs 6, 7, 11)

Type material (all in NHMW). HоLOTYPE: $\delta$ (apterous), NHMW \#5292, "Madagascar, Toamasina Province, Sainte Marie island (Nosy Boraha), Forêt de Kalalao, 18.XI.1993, leg. M. Madl”. AlLotype: + , (apterous), NHMW \#5291, same collection data, except "22.XI.1993”. PARATYPES: 5 우 (apterous), NHMW \#5293-97, same collection data as holotype.

Description. Male. Measurements of holotype: BL 3.7; BW 2.77; HW 1.44; IO 0.47; PW 1.13; PHI 78; TiL 1.81; TaL 0.62; TTI 34. Antenna: A1-A4, 1.85, 0.89, 0.80, 0.58. Fore leg: Fe 1.82, Ti 1.81, Ta 0.12+0.50. Middle leg: Fe
5.35, Ti 3.35, Ta $1.24+0.18$. Hind leg: Fe 5.83, Ti 2.55, Ta $0.23+0.27$.

Structural characteristics. Eyes large, posteriorly surpassing sides of pronotum; their minimum distance on average smaller than in other species. Antennomere 1 with row of ca. 5-8 short oblique setae. Pronotum extremely small, in dorsal view of specimen, shorter than half of head length along midline. Apical process of protibia slender and slightly curved. Metanotum and tergites 1-3 medially fused. Shiny areas of dorsum hardly developed, reduced to pair of small areas at submedial yellow patches of mesonotum and a small zone posteriorly on metanotum. Paramere very narrow, moderately curved all over its length, distal part slender (Fig. 11).

Colour. Yellow marks comparatively small (Fig. 6). On head, anterior mark beween antennal tubercles small, 


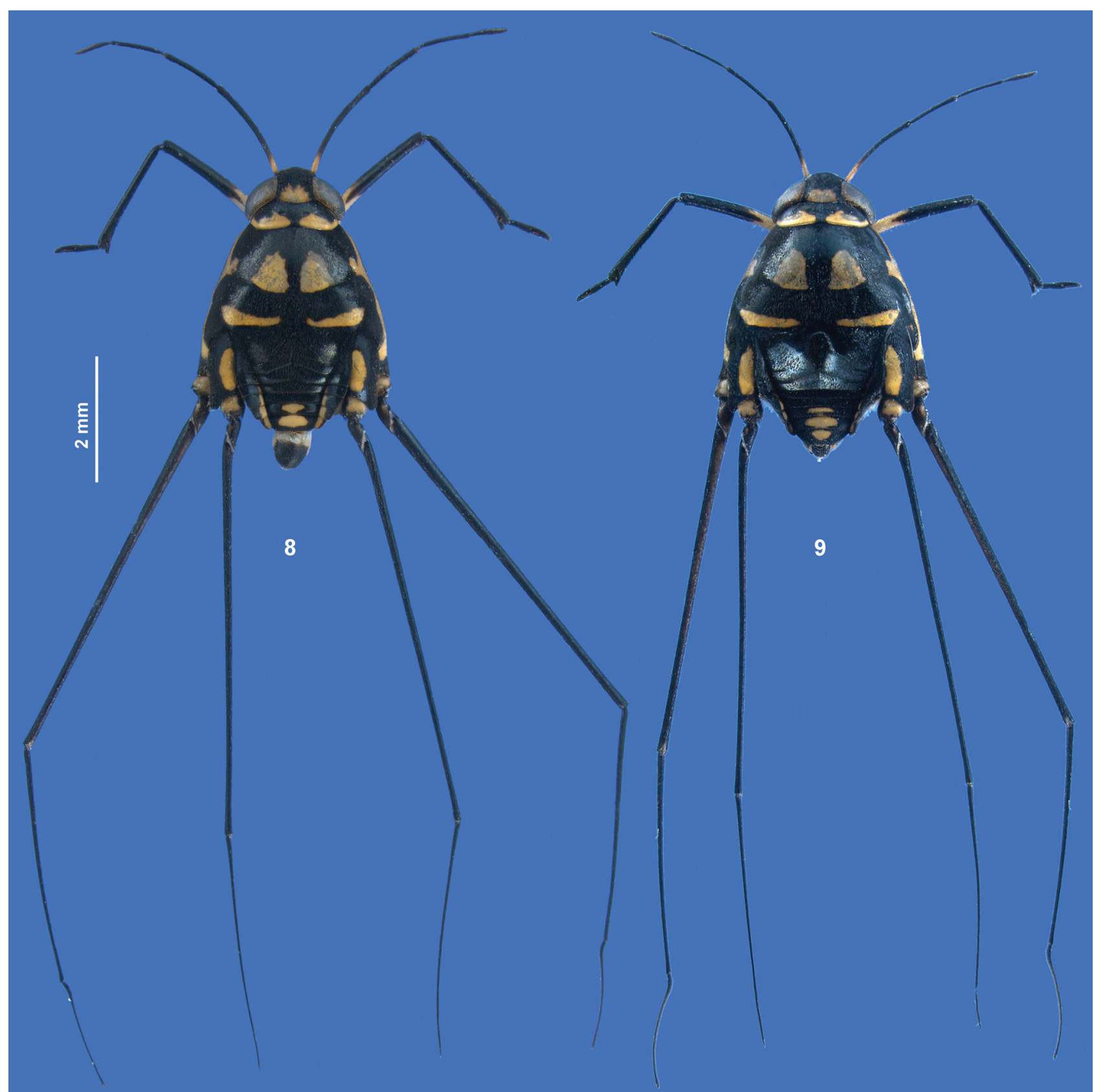

Figs 8-9. Eurymetra papaceki sp. nov., habitus in dorsal aspect: 8 - holotype, male; 9 - allotype, female.

orange, and interrupted in middle. Paired marks on pronotum narrow, medially hardly widened anteriorly, narrower than half-length of pronotum. Paired marks on metanotum widely distant from each other. Metapleuron above spiracle without yellow spot. On abdomen, small yellow marks on tergites 6-7, and on laterotergites 5-7. Body ventrally entirely yellow.

Female. Measurements of allotype: BL 3.7; BW 2.81; HW 1.38; IO 0.44; PW 1.10; PHI 78; TiL 1.58; TaL 0.58; TTI 37. Measurements of other paratypes $(n=5)$ : BL 3.6-3.9; BW 2.75-2.95; HW 1.41-1.47; IO 0.45-0.48; PW 1.10-1.13; PHI 76-78; TiL 1.54-1.60; TaL 0.54-0.59; TTI 36-38.

Structural characteristics. Similar to male. Apical process of protibia slender and less curved. Shiny areas more developed, covering medial parts of tergites 1-3, interrupted by velvety patch; on metanotum posteriorly wide, medially triangularly extended to anterior margin.

Colour. As in male, yellow marks comparatively small (Fig. 7). On head, anterior mark between antennal tubercles small, in some specimens orange, in others interrupted in the middle. Paired marks on pronotum narrow, medially not or only slightly widened. On abdomen, small yellow marks on tergites 6-8, and on laterotergites 4-7 (those on laterotergites 4 and 7 indistinct in some specimens). Body ventrally yellow, mesosternum with large, triangular, blackish brown mark that is anteriorly prolonged until tip of rostrum (only studied in allotype).

Comparative notes. Eurymetra santamariae sp. nov. differs from both other species by the small pronotum (PHI $=76-80$ vs. $85-90)$ and reduced shiny areas on the thoracic nota and tergites. Morphometrically it can also 


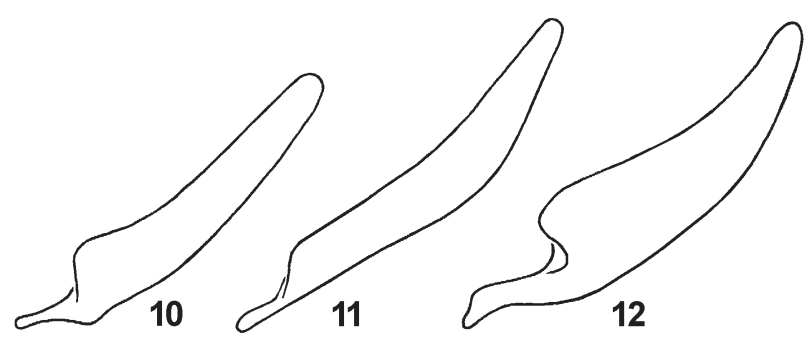

Figs 10-12. Left paramere (lateral aspect): 10 - Eurymetra madagascariensis Poisson, 1945; $11-$ E. santamariae sp. nov.; $12-$ E. papaceki sp. nov.

be distinguished by its smaller size from E. papaceki sp. nov., and by its longer protarsi from E. madagascariensis. Etymology. Named after the French name of the type area, Île Sainte Marie; noun in genitive case in apposition.

\section{Eurymetra papaceki sp. nov.}

(Figs 1-3, 8, 9, 12)

Type material (all in NHMW). HоLотуPE: $\precsim$ (apterous), NHMW \#5303), "Madagascar, Fianarantsoa Province, Ranomafana, 6-10.I.1998, leg. P. Pacholátko". Allotype: 9 (apterous), NHMW \#5306, same locality as holotype. PARATYPes: $7 \delta 6$ † (apterous), NHMW\#5298-5302, 5304, 5305, 5307-5312, same locality as holotype.

Description. Male. Measurements of holotype: BL 4.7; BW 3.17; HW 1.62; IO 0.56; PW 1.41; PHI 87; TiL 2.00; TaL 0.78; TTI 39. Antenna: A1-A4, 1.90, 1.01, 0.88, 0.64. Fore leg: Fe 2.07, Ti 2.00, Ta 0.13 + 0.65. Middle leg: Fe 6.08, Ti 3.87, Ta $1.60+0.22$. Hind leg: Fe 6.37, Ti 3.24, Ta $0.33+$ 0.30 . Measurements of paratypes $(n=7)$ : BL $4.60-4.80 ; \mathrm{BW}$ 3.15-3.32; HW 1.63-1.67; IO 0.54-0.59; PW 1.42-1.48; PHI 86-90; TiL 2.01-2.12; TaL 0.72-0.79; TTI 36-38.

Structural characteristics. Eyes moderately large, posteriorly just reaching base of mesopleuron; their minimum distance on average larger than in other species. Antennomere 1 with row of ca. 4-8 short oblique setae (Fig. 1). Pronotum moderately small, in dorsal view of specimen, longer than half of head length along midline. Apical process of protibia comparatively long, acute, moderately curved. Shiny areas of dorsum strongly expanded, but not on head, extreme sides of thoracic nota, tergite 7 and segment 8, and some narrow zones along sutures laterally. Paramere comparatively broad near its base, from there evenly curved and narrowed towards tip (Fig. 12).

Colour. Yellow marks comparatively large (Fig. 8). Head anteriorly with a pair of large yellow marks, usually separated in the middle. Paired marks on pronotum comparatively wide, in most specimens reaching anterior half medially. Paired marks on metanotum strongly transverse, their distance hardly larger than that of marks on mesonotum. Metapleuron above spiracle usually without a yellow spot, or in some specimens present as a minute dot. On abdomen, small yellow marks on tergites 6-7; marks on laterotergites variably developed, from 6-7 to 3-7. Body ventrally entirely yellow.

Female. Measurements of allotype: BL 4.7; BW 3.35; HW 1.67; IO 0.57; PW 1.48; PHI 89; TiL 1.77; TaL
0.67; TTI 38. Measurements of paratypes $(n=6)$ : BL 4.60-4.70; BW 3.30-3.40; HW 1.60-1.65; IO 0.54-0.57; PW 1.41-1.46; PHI 85-89; TiL 1.76-1.84; TaL 0.68-0.76; TTI 39-42.

Structural characteristics. Similar to male. Apical process of protibia slender and less curved. Shiny areas as expanded as in male, except for the velvety patch (Fig. 2).

Colour. As in male (Fig. 9). On abdomen, yellow marks on tergites 6-8; marks on laterotergites variably developed, from $5-7$ to $3-7$. Body ventrally yellow, mesosternum posteriorly with triangular brown mark that is anteriorly faded; metasternum black (Fig. 3).

Etymology. This new species in named in the memory of Miroslav ("Mirek") Papáček, a reliable colleague in research projects, a gentle person, and a good friend.

\section{Discussion}

Hitherto, all Eurymetra specimens from Madagascar were assigned to a single species, E. madagascariensis (Fossati 2001, Román-Palacios et al. 2018). However, a closer examination of the specimens deposited at the Natural History Museum Vienna revealed an unknown diversity leading to the description of two further species. I expect that more species from Madagascar will be discovered if material becomes available from other parts of this island.

While detailed studies on Asian freshwater halobatines have been carried out since the 1990s (e.g., CHEN \& NIESER 1993a,b; Chen \& Zettel 1999; Tran \& Zettel 2019), the taxonomy and systematics of African and Madagascan genera have remained in a preliminary state. Not much more besides the original descriptions are known of the three genera Eurymetropsis, Eurymetropsiella, and Eurymetropsielloides, which altogether comprise only five species (Román-PALACIOS et al. 2018). The morphology of the nine species of Eurymetra (including the new species) is diverse and the relationship of Eurymetra and the aforementioned genera remains dubious. Scarcity of material is a main obstacle for more comprehensive studies. However, the E. madagascariensis species group is a distinct clade and is well defined by a distinct apomorphic character, the velvety patch on tergites 1-2 of females (Fig. 2). The E. madagascariensis species group differs strongly from the type species of Eurymetra, E. natalensis, e.g., by colour pattern and eye size. However, some African species show similar character states, which further complicates the taxonomic affinities of the E. madagascariensis species group.

\section{Acknowledgements}

I thank the collectors, Michael Madl, Petr Pacholátko, Ernst Pomeisl, and the late Ferdinand Starmühlner, who deposited their Eurymetra specimens in the Natural History Museum Vienna, Harald Bruckner (NHMW) for the preparation of photographs, Alice Laciny for correcting the English, Petr Kment for the invitation to contribute to this volume, and the reviewers Ping-ping Chen and Jakob Damgaard for their remarks. 


\section{References}

ANDERSEN N. M. 1982: The semiaquatic bugs (Hemiptera, Gerromorpha). Phylogeny, adaptations, biogeography and classification. Entomonograph. Vol. 3. Scandinavian Science Press, Klampenborg, $455 \mathrm{pp}$.

CHEN P.-P. \& NIESER N. 1993a: A taxonomic revision of the Oriental water strider genus Metrocoris Mayr (Hemiptera, Gerridae). Part I. Steenstrupia 19: 1-43.

CHEN P.-P. \& NIESER N. 1993b: A taxonomic revision of the Oriental water strider genus Metrocoris Mayr (Hemiptera, Gerridae). Part II. Steenstrupia 19: 45-82.

CHEN P.-P. \& ZETTEL H. 1999: A taxonomic revision of the Oriental water strider genus Ventidius Distant (Hemiptera, Gerromorpha, Gerridae). Tijdschrift voor Entomologie 141: 137-208.

CONSTANT J. 2014: Revision of the Malagasy lanternfly genus Belbina Stål, 1863, with two new species (Hemiptera: Fulgoromorpha: Fulgoridae). European Journal of Taxonomy 102: 1-37.

DAMGAARD J., MOREIRA F. F. F., WEIR T. A. \& ZETTEL H. 2014: Molecular phylogeny of the pond skaters (Gerrinae), discussion of the fossil record and a checklist of species assigned to the subfamily (Hemiptera: Heteroptera: Gerridae). Insect Systematics and Evolution 45: 251-281.

ESAKI T. 1926: The water-striders of the subfamily Halobatinae in the Hungarian National Museum. Annales Musei Nationalis Hungarici 23: $118-164$.

FOSSATI O. 2001: Hétéroptères. Pp. 235-241. In: ELOUARD J.-M. \& GIBON F.-M. (eds): Biodiversité et biotypologie des eaux continentales de Madagascar. Institut de Recherche pour le Développement, Centre National de la Recherche pour l'Environnement \& Laboratoire de Recherche sur les Systèmes Aquatiques et leur Environnement, Montpellier, $447 \mathrm{pp}$.

POISSON R. 1945: Quelques hémiptères aquatiques africains et malgaches. Bulletin de la Société Entomologique de France 50: 87-94.

POISSON R. 1952: Contribution a l'etude des hydrocorises de Madagascar (missions J. Millot et R. Paulian 1949) $3^{\mathrm{e}}$ note. Mémoires de l'Institut Scientifique de Madagascar, Série E 1: 23-70.

POISSON R. 1956: Contribution a l'etude des hydrocorises de Madagascar (Heteroptera). $4^{\mathrm{e}}$ mémorie. Mémoires de l'Institut Scientifique de Madagascar, Série E 7: 243-265.

POLHEMUS D. A. \& ANDERSEN N. M. 2015: Rhagovelia of Madagascar and adjacent Indian Ocean islands (Heteroptera: Veliidae), Part 2: Revision of the tesari species group. Insect Systematics and Evolution 46: 115-220.

POLHEMUS J. T. \& POLHEMUS D. A. 2002: The Trepobatinae (Gerridae) of New Guinea and surrounding regions, with a review of the world fauna. Part 6. Phylogeny, biogeography, world checklist, bibliography, and final taxonomic addenda. Insect Systematics and Evolution 33: 253-290.

ROMÁN-PALACIOS C., DAMGAARD J., CHENG L., MOREIRAF. F. F., IKAWA T., WEIR T. \& ZETTEL H. 2018: Molecular phylogeny of sea-skaters (Halobates Eschscholtz, 1822), relationship between Halobatini and Metrocorini, and a catalogue of the subfamily Halobatinae (Hemiptera: Heteroptera: Gerridae). Insect Systematics and Evolution, 102 pp., DOI 10.1163/1876312X-00002197

TRAN A. D. \& ZETTEL H. 2019: A taxonomical study of the genus Esakia Lundblad, 1933 (Heteroptera: Gerromorpha: Gerridae), with descriptions of two new species from Borneo. Aquatic Insects 40: $1-17$. 